\title{
Reaction of Phenyl Azide with Amides of Malonic Acids and Phenylacetic Acid
}

\author{
MIKAEL BEGTRUP and CHRISTIAN PEDERSEN \\ Organisk-kemisk Laboratorium, Polyteknisk Lareanstalt, Copenhagen, Denmark
}

\begin{abstract}
Reaction of phenyl azide with malonamide, phenylacetamide or their $\mathrm{N}$-methyl derivatives gives mainly 5 -hydroxy-1,2,3-triazoles, unsubstituted or substituted with a methyl group at position 1 . When $\mathrm{C}$-substituted malonamides or their $\mathrm{N}$-methyl derivatives react with phenyl azide the main products are 1-phenyl-5-hydroxy-1,2,3-triazoles.
\end{abstract}

Dimroth has shown that reaction of diethyl malonate with phenyl azide, in the presence of sodium ethoxide, gives 1-phenyl-4-carbethoxy-5-hydroxy1,2,3-triazole (II), probably with a triazene (I) as an intermediate. ${ }^{1}$

In analogy with this one might expect that malonamide (III, $R=H$ ), under similar conditions, would give 1-phenyl-4-carboxamido-5-hydroxy-1, 2,3-triazole $(\mathrm{V}, \mathrm{R}=\mathrm{H})$. Dimroth, ${ }^{2}$ however, found that the reaction took a different course yielding 4-carboxamido-5-hydroxy-1,2,3-triazole (VI, $R=$ $H)$ and aniline, and he assumed that a triazene $(I V, R=H)$ was an intermediate. We have repeated this reaction and obtained a $72 \%$ yield of (VI). No trace of $(V)$ was found.

The reaction of phenyl azide with a number of amides has now been studied. Thus, it was found that $\mathbf{N}, \mathbf{N}^{\prime}$-dimethyl malonamide (III, $\mathrm{R}=\mathrm{CH}_{3}$ ) with phenyl azide gives 1-methyl-4-(N-methyl carboxamido)-5-hydroxy-1,2,3-triazole (VI, $\mathrm{R}=\mathrm{CH}_{3}$ ) in $67 \%$ yield. Again no trace of the compound with structure $\left(\mathrm{V}, \mathrm{R}=\mathrm{CH}_{3}\right)$ could be found.

Phenylacetamide (VII, $\mathrm{R}=\mathrm{H}$ ) gave, when treated with phenyl azide and sodium ethoxide, a mixture of 1,4-diphenyl-5-hydroxy-1,2,3-triazole (IX) and 4-phenyl-5-hydroxy-1,2,3-triazole $(X, R=H)$ with the latter predominating. Again a triazene (VIII, $\mathrm{R}=\mathrm{H}$ ) may be an intermediate in the reaction and if this triazene has the structure (VIIIa, $R=\mathbf{H}$ ) the negatively charged nitrogen may attack the amide-carbon giving (IX) and ammonia. If, on the other hand, the triazene has the tautomeric structure (VIIIb, R $=\mathrm{H}$ ) the amide-nitrogen can attack the middle nitrogen of the triazene with the formation of $(X, R=H)$ and aniline, apparently the latter course of the reaction predominates in this case and is the only one in the case of malona- 

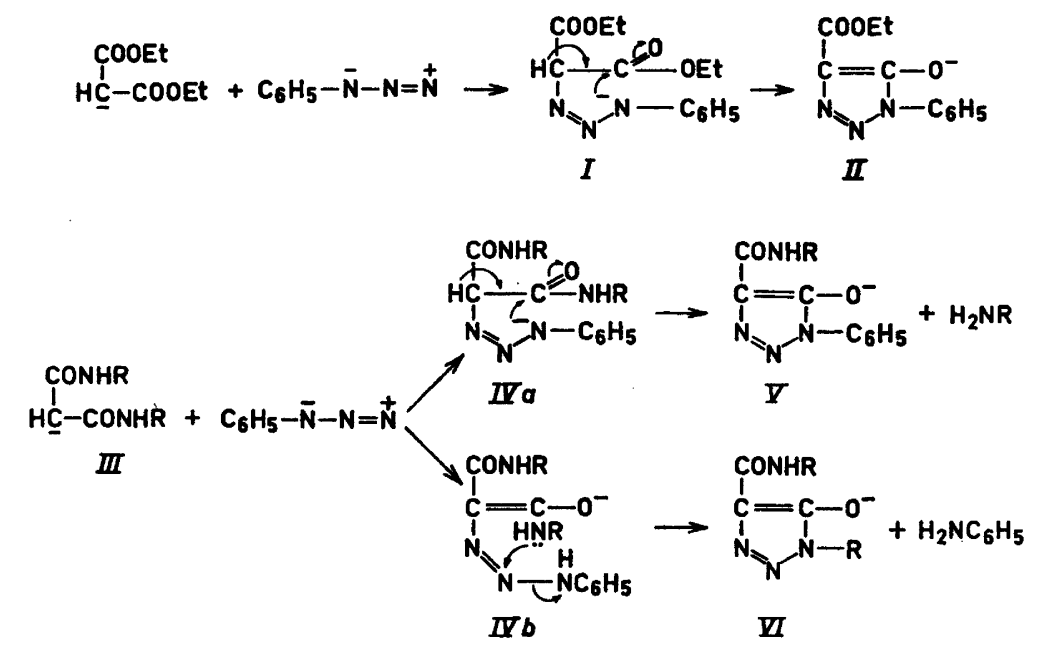

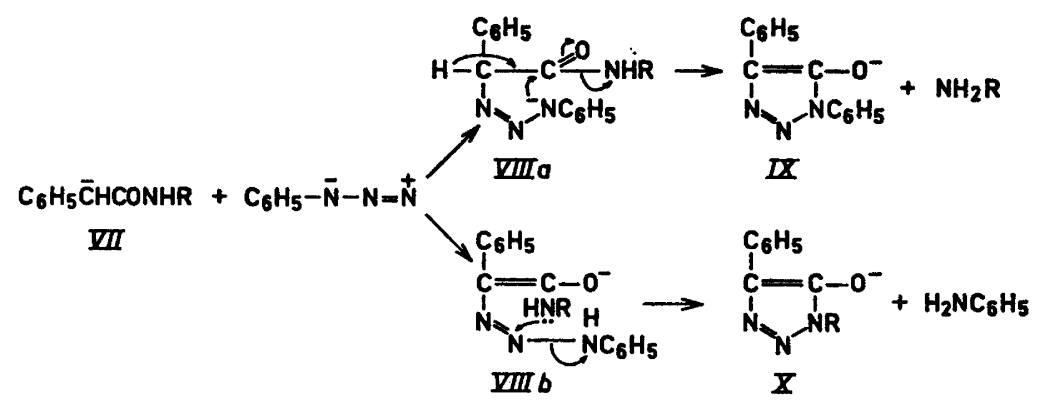

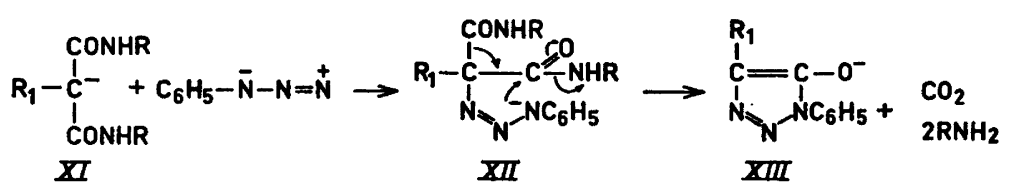

mide or $\mathbf{N}, \mathrm{N}^{\prime}$-dimethyl malonamide where the triazenes (IVa) or (IVb) could be formed. A similar reaction with $\mathrm{N}$-methyl phenylacetamide (VII, $\mathrm{R}=\mathrm{CH}_{3}$ ) gave 1-methyl-4-phenyl-5-hydroxy-1,2,3-triazole $\left(\mathrm{X}, \mathrm{R}=\mathrm{CH}_{3}\right)$ as the only product. The introduction of a methyl group makes the amide-nitrogen more nucleophilic and it is, therefore, understandable that (VIIIb) becomes more reactive at the expense of (VIIIa) and that $(\mathrm{X})$ is the only product.

Reaction of methylmalonamide (XI, $\mathrm{R}=\mathrm{H}, \mathrm{R}_{1}=\mathrm{CH}_{3}$ ) with phenyl azide and sodium ethoxide gave 1-phenyl-4-methyl-5-hydroxy-1,2,3-triazole (XIII, $\mathrm{R}_{1}=\mathrm{CH}_{3}$ ) as the sole product. The same triazole was obtained when $\mathrm{N}, \mathrm{N}^{\prime}$-dimethyl methylmalonamide $\left(\mathrm{XI}, \mathrm{R}=\mathrm{R}_{1}=\mathrm{CH}_{3}\right.$ ) was used. In these two reactions the first step is probably the formation of a triazene (XII, $R_{1}=$ $\mathrm{CH}_{3}, \mathrm{R}=\mathrm{H}$ or $\mathrm{CH}_{3}$ ) which, by attack of the negatively charged nitrogen 
on the amide-carbon and simultaneous loss of the carboxamido group, yields (XIII). The triazene (XII) cannot have the tautomeric structure analogous to $(\mathrm{IVb})$ or (VIIIb) and therefore (XIII) is the only product formed.

Phenylmalonamide ( $\mathrm{XI}, \mathrm{R}=\mathrm{H}, \mathrm{R}_{1}=\mathrm{C}_{6} \mathrm{H}_{5}$ ) gave 1,4-diphenyl-5-hydroxy1,2,3-triazole (XIII, $\mathrm{R}_{1}=\mathrm{C}_{6} \mathrm{H}_{5}$ ) as the main product; a small amount of 4phenyl-5-hydroxy-1,2,3-triazole $(X, R=H)$ was also formed. Similarly $\mathbf{N}, \mathbf{N}^{\prime}$ dimethyl phenylmalonamide $\left(\mathrm{XI}, \mathrm{R}=\mathrm{CH}_{3}, \mathrm{R}_{1}=\mathrm{C}_{6} \mathrm{H}_{5}\right.$ ) gave 1,4-diphenyl5-hydroxy-1,2,3-triazole as the major product together with a small amount of 1-methyl-4-phenyl-5-hydroxy-1,2,3-triazole $\left(\mathrm{X}, \mathrm{R}=\mathrm{CH}_{3}\right)$. The formation of 4-phenyl-5-hydroxy-1,2,3-triazole $(X, R=H)$ and its 1-methyl derivative ( $\mathrm{X}, \mathrm{R}=\mathrm{CH}_{3}$ ) in the latter two experiments may be explained by assuming that part of the triazene (XII) loses a carboxamido group prior to cyclisation. This would lead to the intermediate (VIIIa or b) and thus to (X).

\section{EXPERIMENTAL}

Melting points are uncorrected. The purity of all products was checked by thin layer chromatography on silica gel G using ethyl acetate-propanol-water (5-3-2) as solvent. The spots were detected by spraying with aqueous ferric chloride. Equivalent weights were determined by potentiometric titration with $0.1 \mathrm{~N}$ sodium hydroxide.

\section{Reaction of amides with phenylazide}

Malonamide. The reaction was performed according to Dimroth ${ }^{2}$ yielding $72 \%$ of crude product. Recrystallization from water gave pure 4-carboxamido-5-hydroxy-1,2,3triazole with m.p. 186 - 187 ${ }^{\circ}$ (decomp.) (Dimroth reports m.p. 196 ${ }^{\circ}$ (decomp.)). (Found: C 27.84; $\mathrm{H} 3.18 ; \mathrm{N}$ 43.94. Calc. for $\mathrm{C}_{3} \mathrm{H}_{4} \mathrm{~N}_{4} \mathrm{O}_{2}: \mathrm{C} 28.12 ; \mathrm{H} 3.12 ; \mathrm{N} 43.75$ Equiv. wt.: Found 126; calc. 128).

$N, N^{\prime}$-Dimethyl malonamide. To a solution of sodium $(1.15 \mathrm{~g})$ in ethanol $(25 \mathrm{ml})$ was added $\mathrm{N}, \mathrm{N}^{\prime}$-dimethyl malonamide ${ }^{3}(6.51 \mathrm{~g})$ and phenyl azide $(5.95 \mathrm{~g})$. The mixture was heated on a steam bath for $1 \mathrm{~h}$ during which time the product separated as a sodium salt. The sodium salt was washed with ethanol and dissolved in water $(50 \mathrm{ml})$. Addition of hydrochloric acid yielded a precipitate of $6.6 \mathrm{~g}$ of crude product which on recrystallization from water $(50 \mathrm{ml})$ gave $5.2 \mathrm{~g}(67 \%)$ of 1 -methyl-4-( $\mathrm{N}$-methyl carboxamido $)-5$ hydroxy-1,2,3-triazole, m.p. $184-186^{\circ}$. Two additional recrystallizations caused no change in melting point. (Found: $\mathrm{C} 38.60 ; \mathrm{H} 5.20 ; \mathrm{N} 35.52$. Calc. for $\mathrm{C}_{8} \mathrm{H}_{8} \mathrm{~N}_{4} \mathrm{O}_{2}: \mathrm{C} \mathrm{38.40;} \mathrm{H} \mathrm{5.16}$; N 35.85. Equiv. wt.: Found 157; calc. 156).

Phenylacetamide. To a suspension of sodium ethoxide $(1.77 \mathrm{~g})$ in ethanol $(15 \mathrm{ml})$ (when larger amounts of ethanol were used the yield of products was much lower) was added phenylacetamide $(3.50 \mathrm{~g})$ and phenyl azide $(3.1 \mathrm{~g})$ and the mixture was heated on a steam bath for $6 \mathrm{~h}$. The ethanol was then removed in vacuo, water $(40 \mathrm{ml})$ was added and the mixture was extracted with methylene chloride to remove unreacted material. The aqueous phase was acidified and cooled yielding $2.4 \mathrm{~g}$ of a product which, by thin layer chromatography, was shown to contain two compounds. The product was extracted with ether $(5 \times 15 \mathrm{ml})$, the ether was removed and the residue was recrystallized twice from benzene yielding $1.0 \mathrm{~g}(24 \%)$ of 4-phenyl-5-hydroxy-1,2,3-triazole, m.p. 176-178. After two additional recrystallizations the product was chromatographically pure, m.p. $178-180^{\circ}\left(\right.$ reported $^{4}$ m.p. $184^{\circ}$ ). (Found: C 59.60; $\mathrm{H} 4.30 ; \mathrm{N} 26.10$. Calc. for $\mathrm{C}_{8} \mathrm{H}_{7} \mathrm{~N}_{3} \mathrm{O}$ : C 59.62; H 4.38; N 26.07. Equiv. wt.: Found 158; calc. 161).

The ether-insoluble material was chromatographically pure; recrystallization from ethanol gave $0.50 \mathrm{~g}(8 \%)$ of 1,4-diphenyl-5-hydroxy-1,2,3-triazole, m.p. 155-156 ${ }^{\circ}$. Two additional recrystallizations led to an increase of the melting point to $157-158^{\circ}$ (recorded ${ }^{2} 150-151^{\circ}$ ). (Found: $\mathrm{C} 70.60 ; \mathrm{H} \mathrm{4.90;} \mathrm{N}$ 17.72. Calc. for $\mathrm{C}_{14} \mathrm{H}_{11} \mathrm{~N}_{3} \mathrm{O}$ : $\mathrm{C} 70.86$; $H$ 4.67; $N$ 17.72). The melting point and the infrared spectrum of the produot were identical with those of a sample prepared according to Dimroth. ${ }^{1}$

Acta Chem. Scand. 18 (1964) No. 6 
$N$-Methyl phenylacetamide. By the procedure described above $7.51 \mathrm{~g}$ of N-methyl phenylacetamide ${ }^{5}$ gave 5.50 g of chromatographically pure product, m.p. $200^{\circ}$. Recrystallization from ethanol gave $3.1 \mathrm{~g}(55 \%)$ of pure 1-methyl-4-phenyl-5-hydroxy-1,2,3-triazole, m.p. 203․ (Found: C 61.50; H 5.00; N 23.80. Calc. for $\mathrm{C}_{9} \mathrm{H}_{9} \mathrm{~N}_{3} \mathrm{O}: \mathrm{C} 61.70 ; \mathrm{H} 5.17 ; \mathrm{N} 23.99$. Equiv. wt.: Found 175; calc. 175).

Methylmalonamide. To a suspension of sodium ethoxide $(10.2 \mathrm{~g})$ in ethanol $(20 \mathrm{ml})$ was added methylmalonamide $\theta^{\circ}(5.81 \mathrm{~g})$ and phenyl azide $(5.95 \mathrm{~g})$ and the mixture was heated on a steam bath for $6 \mathrm{~h}$. The solvent was then removed in vacuo, water was added and the mixture was extracted with methylene chloride. Acidification of the aqueous phase caused precipitation of $5.6 \mathrm{~g} \mathrm{(64 \% )} \mathrm{of} \mathrm{1-phenyl-4-methyl-5-hydroxy-1,2,3-triazole}$ with m.p. $148^{\circ}$ (decomp.). Recrystallization from water caused no change in melting point. (Found: C 61.70; $\mathrm{H} 5.39 ; \mathrm{N} 23.94$. Calc. for $\mathrm{C}_{9} \mathrm{H}_{9} \mathrm{~N}_{3} \mathrm{O}: \mathrm{C} 61.70 ; \mathrm{H} 5.17 ; \mathrm{N} 23.99$. Equiv. wt.: Found 175; calc. 175). Dimroth ${ }^{7}$ found m.p. $133-134^{\circ}$ for this compound. However, a sample prepared according to Dimroth gave m.p. $147-148^{\circ}$ (decomp.) and had the same infrared spectrum as the material prepared above.

$N, N^{\prime}$-Dimethyl methylmalonamide. In the same way $\mathrm{N}, \mathrm{N}^{\prime}$-dimethyl methylmalonamide $^{8}(7.21 \mathrm{~g})$ gave $9.59 \mathrm{~g}$ of crude product which by recrystallization yielded $6.22 \mathrm{~g}$ (71 \%) of 1-phenyl-4-methyl-5-hydroxy-1,2,3-triazole, m.p. $148^{\circ}$.

Phenylmalonamide. Analogously phenylmalonamide ${ }^{\bullet}(8.91 \mathrm{~g})$ gave $3.67 \mathrm{~g}$ of a crude product which by thin layer chromatography was shown to contain two main components and traces of other compounds. Separation and purification as described under phenylacetamide gave $3.19 \mathrm{~g}(27 \%)$ of 1,4-diphenyl-5-hydroxy-1,2,3-triazole and $0.26 \mathrm{~g}(6 \%)$ of 4-phenyl-5-hydroxy-1,2,3-triazole.

$N, N^{\prime}$-Dimethyl phenylmalonamide. From $10.31 \mathrm{~g}$ of $\mathrm{N}, \mathrm{N}^{\prime}$-dimethyl phenylmalonamide $10.43 \mathrm{~g}$ of crude product was obtained. A thin layer chromatogram showed two spots. The product was recrystallized twice from a mixture of ethanol (ca. $400 \mathrm{ml}$ ) and water $(c a .800 \mathrm{ml})$ yielding $9.25 \mathrm{~g}(78 \%)$ of chromatographically pure 1,4-diphenyl-5-hydroxy -1,2,3-triazole, m.p. 155 . Evaporation of the combined mother liquors followed by recrystallization from ethanol gave $0.77 \mathrm{~g}$ of product. Chromatography showed one spot corresponding to 1-methyl-4-phenyl-5-hydroxy-1,2,3-triazole; but the compound could not be isolated in a pure state.

$\mathrm{N}, \mathrm{N}^{\prime}$-Dimethyl phenylmalonamide was prepared from dimethyl phenylmalonate and aqueous methylamine. The product was recrystallized from ethanol, m.p. $193^{\circ}$. (Found: C 64.10; $\mathrm{H}$ 7.05; $\mathrm{N}$ 13.78. Calc. for $\mathrm{C}_{11} \mathrm{H}_{14} \mathrm{~N}_{2} \mathrm{O}: \mathrm{C} 64.04 ; \mathrm{H} 6.84 ; \mathrm{N} 13.58$ ).

The authors are indebted to cand.pharm. I. Krogh Andersen for the infrared spectra. Microanalyses were made by Mr. Preben Hansen.

\section{REFERENCES}

1. Dimroth, O. Ann. 335 (1904) 6.

2. Dimroth, O. Ann. 373 (1910) 344.

3. Freund, M. Ber. 17 (1884) 133.

4. Hohenlohe-Oehringen, K. Monatsh. 89 (1958) 597.

5. Taverne, H. V. Rec. Trav. Chim. 16 (1897) 34.

6. Meyer, H. Monatsh. 27 (1906) 31.

7. Dimroth, O. and Letsche, E. Ber. 35 (1902) 4056.

8. Franchimont, A. P. N. Rec. Trav. Chim. 4 (1885) 195.

9. Dox, A. W. and Yoder, L. J. Am. Chem. Soc. 44 (1922) 1564.

Received April 10, 1964. 